\title{
Neglected diseases get vaccine research boost
}

Swiss pharmaceutical giant Novartis has opened a non-profit research institute in northern Italy to develop vaccines for neglected diseases prevalent in the developing world.

The new Novartis Vaccines Institute for Global Health is based in Siena, the home of Novartis Vaccines and Diagnostics. It will be managed independently of the commercial vaccine company and will have its own team, focusing initially on diarrhoeal diseases that have been overlooked by the major research funders. "Diarrhoeal diseases cause more deaths per year among children under five than malaria and AIDS together," says Rino Rappuoli, global head of vaccine research at Novartis, who has been the force behind the venture.

"Diarrhoeal diseases cause more deaths in children under five together."

Rappuoli has spent his entire career in vaccine research, joining the Sclavo Institute in Siena 30 years ago, and seeing it through its takeover by Chiron in 1992 and then by Novartis two years ago. "I've had to develop vaccines for the rich world, where our customers are - but I knew how easily our technology and knowledge could be applied to vaccines for the poor world," he says.

The new institute will be headed by Allan Saul, who led the malaria vaccine programme than malaria and AIDS at the US National Institute of Allergy and Infectious Diseases before moving to Novartis last year. The plan is to develop a polyvalent vaccine (effective against more than one strain) for three forms of Salmonella infection and a polyvalent vaccine for Shigella and ETEC (enterotoxigenic Escherichia coli). Over the next few years, other diseases will be targeted.

Choosing the diseases to focus on was tricky, Saul says. "We started with a list of 57 and whittled it down to a short list of five - all diarrhoeal diseases - where we thought we could get the best return on investment: these diseases kill millions each year, and we can build on existing basic research."

The institute complements the Novartis Institute for Tropical Diseases, another non-profit organization founded five years ago in Singapore to develop drugs for diseases such as malaria, tuberculosis and dengue fever. The vaccine institute hopes to recruit up to 20 scientists by 2009 , and eventually to have around 80 staff working on four programmes. Novartis will pay the institute's staff and running costs, but most of its project money will have to be sought from other sources, such as the Bill \& Melinda Gates Foundation.

Alison Abbott

\section{SNAPSHOT 'Doomsday vault' opens}

The glittering entrance to the Svalbard Global Seed Vault leads into a 100-metre tunnel dug in the side of a cave at Longyearbyen, a remote Arctic archipelago in Norway. Its first batch of seeds was accepted on 26 February - the initial stage in a plan to provide a repository holding back-up copies of seeds representing almost every food crop in existence.

At its launch, Jacques Diouf, head of the United Nations Food and Agriculture

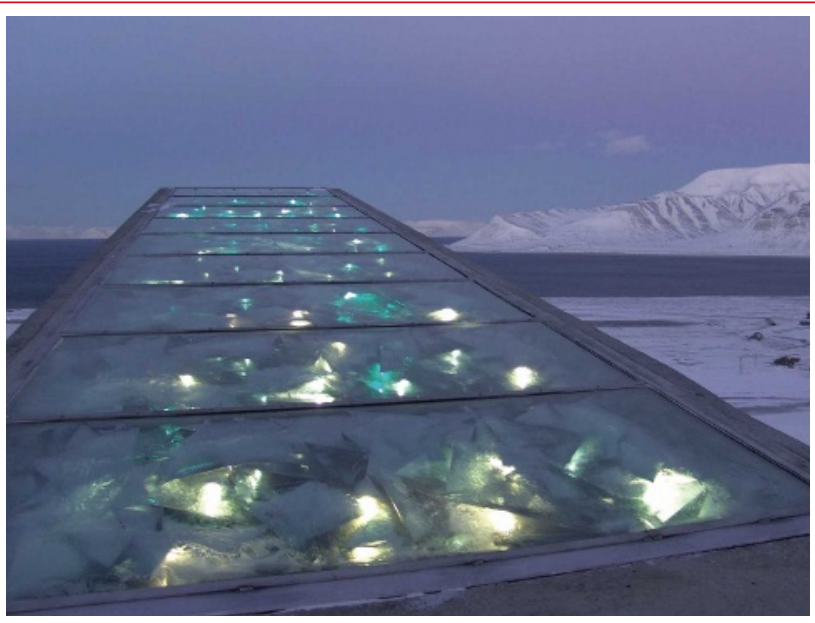

Organization, described the project as "one of the most significant acts in the preservation of humanity". Michael Hopkin
ON THE RECORD

“We are not recommending you import alligators into California. That would not be a good idea."

Zoologist Gordon Rodda from the US Geological Survey in Colorado pours cold water on a tactic to prevent a feared invasion of Burmese pythons in San Francisco.

\section{SCORECARD}

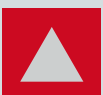

The Galapagos Ecuador's president Rafael Correa has pledged to stamp out the use of fossil fuels on the Galapagos Islands by 2015 , starting with a huge wind farm that will halve their diesel requirements.

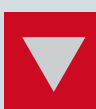

The Amazon Ecologists say that the 60-metre-wide protected rainforest corridors flanking many of the Amazon's rivers are too narrow to conserve biodiversity. They are calling for government action to raise the minimum width to 400 metres.

\section{OVERHYPED}

\section{Gravity lamp}

The inventor of a gravitypowered lamp - Clay Moulton from Virginia Polytechnic Institute in Blacksburg - has been forced to admit that his device would be too weak to power current light-emitting diodes.

\section{ROBOT NEWS}

\section{Java Justine}

A coffee-making robot has been developed by Italian (of course) scientists. Sceptics who argue that coffee machines already have the automated-coffee-making market sewn up should note that the robot, called Justine, can also tidy clothes off the floor.

Sources: EurekAlert, Conserv. Biol., San Francisco Chronicle, Virginia Tech News, Spiegel 